\title{
Geological processes and the management of groundwater resources in coastal areas
}

\section{H. Kooi \& J. Groen}

Department of Hydrology and Hydrogeology, Faculty of Earth and Life Sciences, Vrije Universiteit, De Boelelaan 1085, 1081 HV, Amsterdam, the Netherlands. kooi@geo.vu.nl.

Manuscript received: January 2002; accepted: January 2003

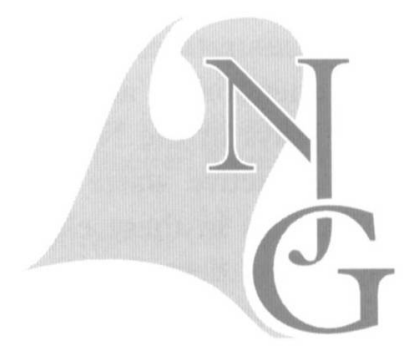

\begin{abstract}
In this contribution, a case is made for the significance of sedimentation and sea-level change for groundwater management of coastal areas. In groundwater practice these geological processes are rarely considered. The role of sediment loading in causing anomalous fluid pressures and flow fields in relatively shallow aquifer systems is discussed and illustrated via both case studies and generic modelling studies. The role of sea-level changes in controlling current salinity distributions is discussed likewise. Central in the discussion is the concept of memory of groundwater systems, which provides the basic reason why processes that were operative in the geological past are still of relevance today. It is argued and shown that awareness and knowledge of the influence of sediment loading and sea level change on current hydrological conditions can lead to improved characterization of the distribution of hydraulic parameters and of the distribution of water quality in coastal areas. This improved characterization, in turn, serves to enhance the validity of impact assessment studies for the long-term development and management of those areas.
\end{abstract}

Keywords: ground water, water resources, water management, paleohydrology, sea-level changes, sedimentation

\section{Introduction}

Groundwater obviously is the quintessential geofluid. In this sense, geofluid research would encompass the entire field of hydrogeology. Yet, 'Geofluids meetings' are not known to be swamped by many hundreds of hydrogeologists from over the world every other year. The main reason for this - apart from the fact that hydrogeologists have their own fora - probably resides in a part of the inherited working definition of what constitutes geofluid research, namely that it focuses on geological time scale processes. Apparently, this part of the definition poses a severe constraint. This primarily reflects the fact that virtually all groundwater research revolves around shorter time scale phenomena. Also, much of the focus of hydroge- ological research is on processes induced by the activities of man rather than natural processes. Indeed, to many hydrologists - in particular to those with an engineering background - 'geology' or 'the geological model' merely implies the spatial distribution of permeability, porosity and other hydraulic parameters in the subsurface; the framework (porous medium) through which groundwater flow and transport takes place. Geological time scales and geological processes are rarely considered. The main reason for the limited attention for geological time-scale processes is that there has been no practical need to do so (e.g., Committe on Opportunities in the Hydrologic Sciences, 1991). Hydrologists had to meet the rapidly growing demand for water supply and sanitation for the everincreasing population and degree of industrialization. 
This was primarily a technical issue with local water availability as the prime constraint.

It may be anticipated, however, that in the coming decades geological processes will assume a greater role in hydrogeology. This prediction is based on the fact that with the growing scale of water supply projects, water scarcity and negative environmental impacts such as salt-water intrusion, land subsidence, desiccation and contamination have started to become main concerns over the last decades. Due to these developments, hydrogeologists may - again for practical reasons - be forced to pay greater attention to conditions deeper in the Earth's crust. Additionally, the issue of sustainable groundwater management of very large national and sometimes transnational domains has become firmly established on the political agenda of many organizations. The management of groundwater implies a thorough understanding of both the distribution and the dynamics (local and regional water balances) of these waters. Evaluation of these two aspects ideally should be based on a large number of observations of water quality, fluid pressure or piezometric head and hydraulic properties of the subsurface sediments. These data are then integrated into a quantitative regional hydrogeological model that characterizes the present condition. Such a model basically serves as a sophisticated, processbased, spatial interpolator/extrapolator of the observational data, which fills-in or predicts attributes of the hydrological system for locations where observations are lacking. When such spatial characterization is achieved, it can be used as a basis (initial condition) for temporal predictions/extrapolations, notably in impact-assessment studies, to realistically evaluate scenarios of water use. An important point is that due to the immense scale of the management domains, data will always be scarce, which introduces major uncertainties in predictions. To reduce the uncertainties associated with characterization of the current situation at these scales, comprehensive understanding of the genesis of available fresh water resources as well as that of adjacent more saline waters that may thwart exploitation activities is of great value. This does imply attention for longer time scales as well as for geological processes. To what extent such a trend toward greater use of geological process knowledge may be reflected by the future participation of hydrogeologists at geofluids meetings remains an open question.

The aim of this paper is to make a case for the significance of the processes of sedimentation and sealevel change, operating at geological time scales, for groundwater management. The focus is on coastal areas, the management of which is particularly complex and important due to high population density, the presence of valuable ecosystems such as wetlands, problems of land subsidence, and the proximity of saline seawater. The relevance of the geological processes is discussed and illustrated with a number of case studies and generic process studies carried out by the authors in the recent past, augmented with discussion of a few related studies by other workers. The presentation takes, therefore, to some extent, the form of a review paper, without attempting to be exhaustive. It starts with a concise introduction of the concepts of 'memory' and 'response time' of groundwater systems, which provide a useful framework for evaluating the significance of geological timescale processes. Then the role of sediment loading in causing anomalous fluid pressures and flow fields and the role of sea-level changes in engendering non-equilibrium salinity distributions are discussed, respectively. Finally, the implications of the findings for groundwater management are evaluated.

\section{Memory in groundwater hydrological systems}

Over the years, systems theory has established itself firmly in the Earth Sciences and has proven extremely fruitful in engendering major advances in the various Earth Science disciplines. The field of groundwater hydrology is no exception to this. One of the basic tenets of system thinking - the existence of equilibria - underlies the so-called 'stationary groundwater models' which, for instance, directly calculate the ultimate drawdown that will results from pumping. Nonstationary groundwater models capture a second tenet of systems theory; that of the tendency for a system to evolve to a new equilibrium if the system is perturbed. Although best known in applications to well-flow problems, the above systems concepts can also be applied to other variables that characterise groundwater systems such as water qualities or temperature and to groundwater flow systems at the scale of entire nations or continents.

For the present discussion, the time scale on which a groundwater system adjusts to a new equilibrium for a given change in boundary conditions is of particular interest. This time scale can be considered a measure of the memory of a system, because its momentary state - that is, the flow field or the solute or temperature distribution at a given time - is determined by the past boundary conditions over that time scale. Conditions further back in time cease to be of relevance. For instance, if draw-downs due to pumping around a pumping well are increasing, the onset of pumping started recently enough to be reflected by the system (the timing may even be inverted from the 
draw-downs). Conversely, if the draw-downs are stationary, the system contains no information on the timing of pumping activities other than that they are older than the reaction time scale of the system.

The time scale on which a groundwater system adjusts to a new equilibrium, or its memory, (in the following referred to as response time), can range from mere seconds to millions of years, depending on the spatial scale of the system, its material properties and which variable of the system is considered. The higher values in this range imply that conditions that occurred thousands to millions of years ago still affect groundwater systems today.

\section{Anomalous fluid pressures and flow fields}

\section{Memory of flow systems}

Groundwater flow is governed by Darcy's law, which states that the flow velocity is proportional to the gradient of head (for non-uniform density fluid, gradients of fluid pressure and fluid density are involved). The head or pressure distribution and the flow are therefore directly coupled, which implies that they have the same response time. Combining Darcy's Law with the continuity principle leads to the well known diffusion equation for head or fluid pressure. From this equation, the response time, $\tau_{p}$, of the fluid pressure/head and the flow field of a groundwater system can be readily derived (e.g., Neuzil, 1986). It is controlled by the hydraulic diffusivity, $D_{h}$, of the sediments and a measure of the spatial scale, $L$, of the system, where hydraulic diffusivity is defined as

$$
D_{h}=\kappa / S_{s}
$$

Here $\kappa$ and $S_{s}$ hydraulic conductivity and specific storage, respectively. For one-dimensional flow and uniform diffusivity, the response time is given by

$$
\tau_{p}=L^{2} / D_{h}=L^{2} S_{s} / \kappa \text {. }
$$

For multidimensional flow the exact response depends on the domain geometry and boundary conditions, but (2) still provides a useful measure of the approximate behaviour (Neuzil, 1986). For non-uniform hydraulic properties, $\tau_{p}$ is controlled by weighted averages of the hydraulic diffusivities. Equation (2) shows that large response times are favoured by large systems with high specific storage (compressibility) that are controlled by low conductivity. These conditions apply, in particular, to deep and confined parts of sedimentary basins. Taking typical values of $L=$ $1 \mathrm{~km}$ (thickness of compressible basin sediments), $S_{\mathrm{s}}$ $=10^{-4} \mathrm{~m}^{-1}$ (inelastic compaction), and $\kappa_{2}=10^{-11} \mathrm{~m} / \mathrm{s}$ (shale) yields a response time of more than 300,000 years. Even larger response times typify hydraulic systems in many places around the world (Kooi, 1997). These large response times find expression in compaction-driven flow phenomena and land subsidence.

\section{Compaction-induced flow}

Sediment loading is a process that is seldom considered in hydrogeology because it is deemed too slow to affect the flow systems that are of interest in hydrogeology practice. For instance, the rate of loading (units of pressure per time) is about one million times smaller than tidal loading. However, in contrast to barometric and tidal loading, sediment loading is monotonic (it doesn't change to unloading) over very long periods of time. Moreover, sediment loading is 'too slow' only for shallow, unconfined groundwater systems that hydrogeologists are mostly concerned with. As explained above, deeper confined parts of sedimentary basins can have response times of the order of a hundred thousand years or more. For a sedimentation rate of $1 \mathrm{~mm} / \mathrm{yr}$, a load corresponding to $100 \mathrm{~m}$ of sediment accumulates in that amount of time. A large part of this load will, therefore, be carried by the groundwater, leading to 'artesian conditions' that are not related to lateral inflow of waters from regions with elevated water tables. The mechanism that leads to these overpressures is often referred to as 'compaction disequilibrium' (Dickinson, 1953). Such overpressures due to sediment loading are very common in sedimentary basins and are well known to workers in the oil- and gas industry (e.g., Powley, 1990; Hunt, 1990). At depths of about $3 \mathrm{~km}$, the pressures often reach values that correspond to piezometric heads of several kilometres above sea level. Towards the surface, these pressures rapidly decrease. However, even relatively small anomalous heads can have a significant effect on the groundwater flow field in areas where topographically-induced hydraulic gradients are low, such as in deltas.

Fig. 1 shows artesian heads in the Burnside aquifer in the coastal area of Suriname (South America) that are too high to be caused by the inland topography or buoyancy forces (Groen, 1998), because the heads in the overlying aquifer are lower. The heads in the Burnside aquifer are attributed to the rapid accumulation of Holocene sediments that derive from the Amazon basin. Numerical modelling shows that a hydraulic conductivity of $2 \cdot 10^{-9} \mathrm{~m} / \mathrm{s}$ is required for the $20 \mathrm{~m}$ thick confining layer overlying the artesian aquifer to explain a head of $1 \mathrm{~m}$. This corresponds to a resistance (one over the leakance) of about 100,000 days. The inferred conductivity is very reasonable for a relatively pure marine clay (Neuzil, 1994). Clearly, if 


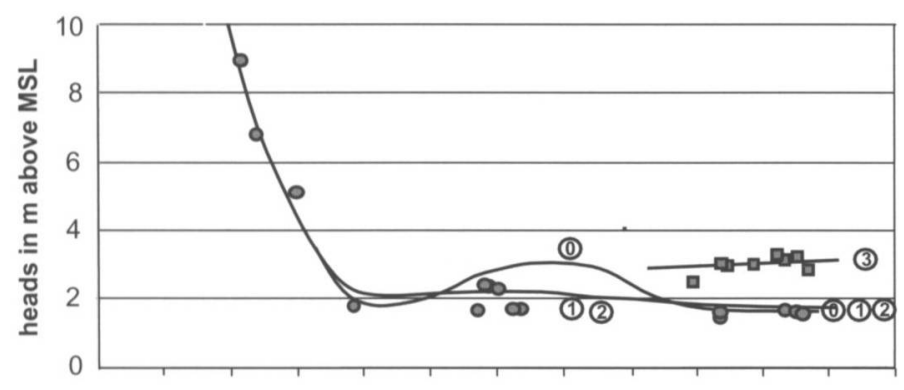

Fig. 1. Overpressuring in a confined aquifer (3) due to Holocene sedimentation in the coastal plain and continental shelf of Suriname. (0) phreatic groundwater; (1) Zanderij aquifer; (2) Coesewijne aquifer; (3) Burnside aquifer.

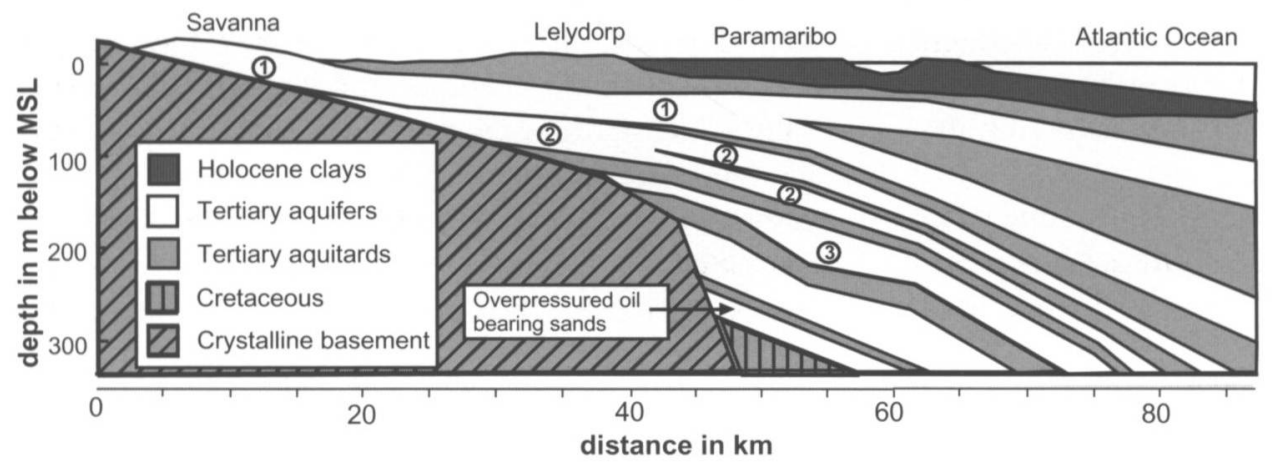

sediment loading were not considered, either the head distribution could not be explained, or a very complicated permeability distribution and flow regime would have to be assumed, with some narrow high-permeability conduit connecting the Burnside aquifer with an inland location with a high topographic head.

The above example from Suriname pertains to an aquifer that is enclosed on all sides by low-permeability sediments or rock. The question arises to what extent sediment loading is relevant in another commonly occurring situation in which an aquifer is semi-confined at the top, but where this confining layer is locally absent in topographically elevated where the aquifer crops out (Fig. 2a) and where it is subject to recharge (elevated water table).

Kooi (1999) recently presented a generic, mathematical analysis of the competition between topography- and compaction-driven flow for this configuration. The analysis shows that the sediment loading can significantly alter the head distribution and flow field in the aquifer and that the basinward directed topography-driven flow can be completely reversed for topographic heads in the recharge area of the order of $1 \mathrm{~m}$ and sedimentation rates of the order of 4 $\mathrm{m} / \mathrm{ky}$ (Fig. 2b). Since sedimentation rates are usually lower than this, the importance of sediment loading for the flow regime in this configuration is typically subtle. However, ignoring the compaction contribution to the flow field may lead to an overestimate of the hydraulic properties of the confining layer.

Finally, knowledge of compaction-driven flow and transport obviously is of paramount importance in radio-active waste disposal research, where the long- term response of aquitard and aquifer systems have to be predicted in order to provide safe storage conditions. However, this topic is considered beyond the scope of the present paper.

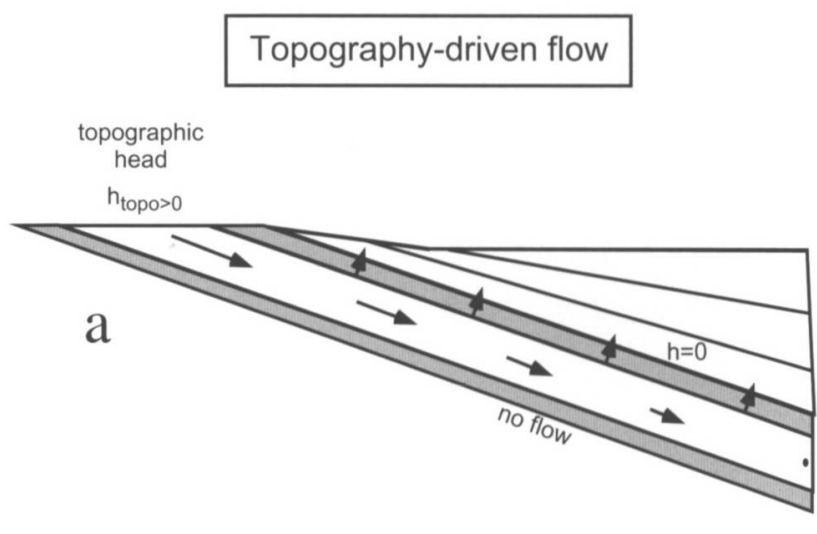

Topography- and compaction-driven flow

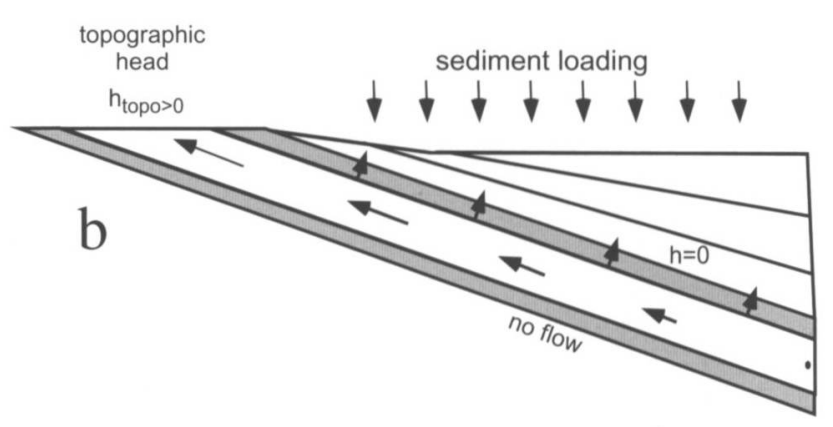

Fig. 2. Schematic illustration of the competition between topography- and compaction-driven flow in a semi-confined aquifer. Modified after Kooi (1999). 


\section{Anomalous salinity distributions}

Besides inducing high fluid pressures and groundwater flow, sediment loading also contributes to land subsidence due to compaction of basin sediments. In areas of active deposition, the subsidence is often compensated by the accumulation of sediments themselves. However, if sedimentation is greatly reduced or stopped - as occurred in many of the world's major deltas due to human intervention in the river systems - compaction and land subsidence continues far into the future. This time lag of compaction-driven land subsidence relative to sediment loading is governed by the same response time as that of the fluid pressure discussed above and, therefore, can be exceedingly large. This time lag in compaction response is the basis of oedometer tests and consolidation theory. Numerical modelling carried out for the western part of the Netherlands (Kooi \& deVries, 1998) and for the Nile Delta, Egypt (Fig. 3) yields current rates of land subsidence of the order of 0.1 $\mathrm{mm} / \mathrm{yr}$ and $0.5 \mathrm{~mm} / \mathrm{yr}$ respectively.

This subsidence is mainly caused by the rapid sedimentation that occurred during the early Holocene, some 7,000 years ago. Although not particularly high compared with land subsidence due to pumping activities, this natural component of subsidence extends over very large areas and will persist for thousands of years.

\section{Memory of water quality patterns}

Whereas the response of groundwater flow systems and pressure fields is governed by one single process, hydraulic, or pressure diffusion, at least three processes can be distinguished that affect the response of water quality patterns: advection, chemical diffusion/dispersion, and chemical reactions. This complicates the analysis of temporal adjustments of water quality considerably. For salinity distributions that are mainly determined by conservative chloride ions, reaction processes are generally not very important and will be ignored here.

The response time of chemical diffusion is given by

$$
\tau_{d}=L^{2} / D_{c}
$$

which is the same as (2), but with hydraulic diffusivity replaced by chemical diffusivity. Values of $D_{c}$ (typically $10^{-10} \mathrm{~m}^{2} / \mathrm{s}$ ) are orders of magnitude smaller than hydraulic diffusivities, even for very tight shales. Therefore, the memory of systems dominated by chemical diffusion is exceedingly large. For instance, a $10 \mathrm{~m}$ thick clay layer has a diffusion response time of more than 30,000 years.

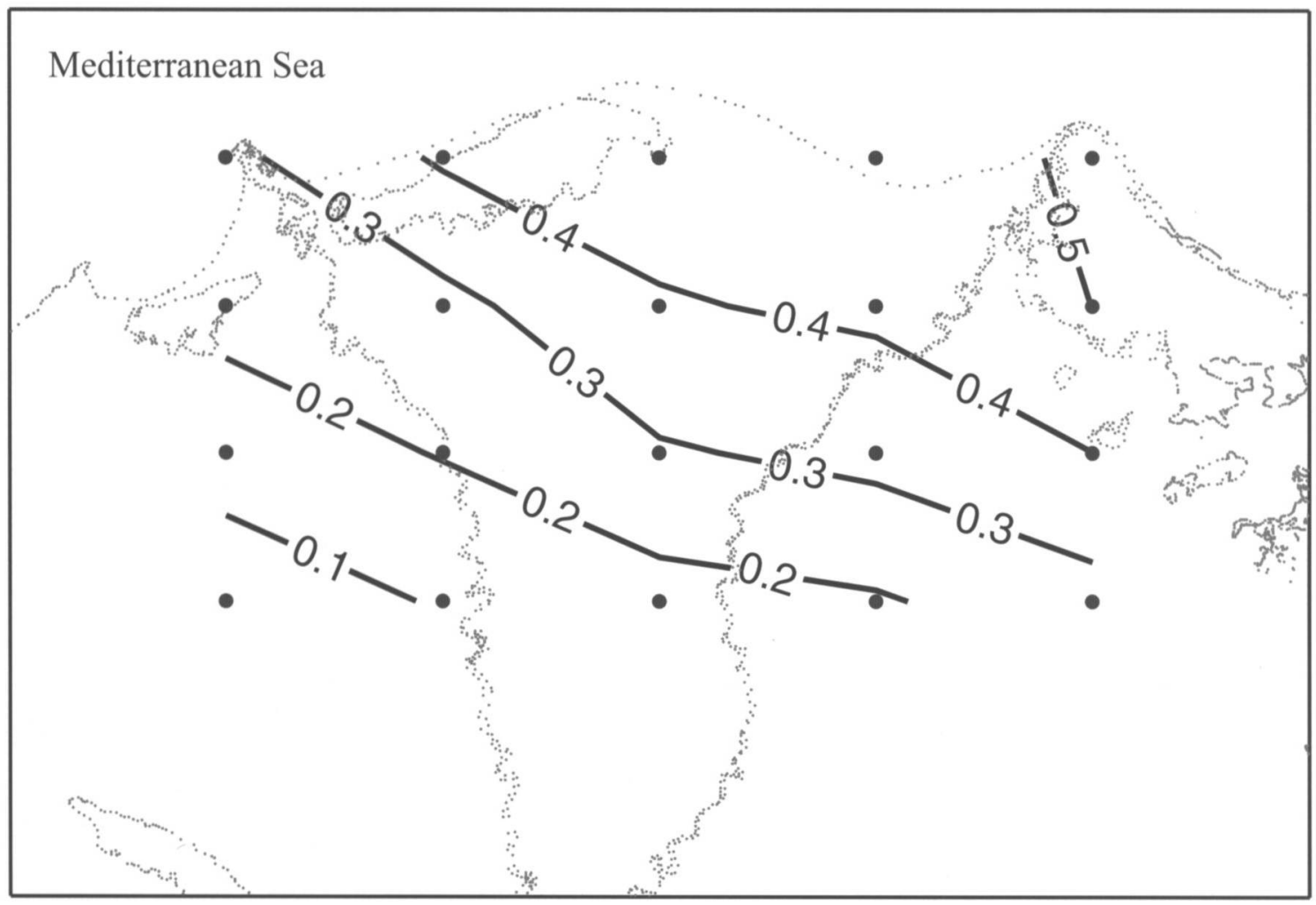

Fig. 3. Current land subsidence due to compaction ( $\mathrm{mm} / \mathrm{yr}$ ) in response to Pleistocene and Holocene sediment loading in the northern part of the Nile Delta, Egypt, predicted by numerical modelling.

$$
\text { -... }
$$


The response time of advection is given by

$$
\tau_{v}=L / v
$$

where $v$ is a characteristic groundwater flow velocity and $L$ the length of the corresponding flow path. Thus, advection response times tend to be large in domains with low flow velocities, such as in deep, confined formations, and in aquifers where advective transport takes place over a large distance. For instance, for a groundwater flow system with horizontal scale of $100 \mathrm{~km}$, a horizontal flow velocity of $1 \mathrm{~m} / \mathrm{yr}$, which is typical for relatively shallow aquifer systems in deltaic areas, already yields a response time of 100,000 years. At these time scales, major geologic and climatic changes occurred at the coastal areas around the world. These changes should, therefore, be taken into consideration when studying current salinity distributions in coastal areas, even in relatively shallow aquifer systems.

\section{Offshore groundwater resources}

Observations of ocean drilling programs, offshore oil wells and water wells on islands provide evidence that fresh and brackish groundwater does not only occur onshore, but in some places extends 10 to $100 \mathrm{~km}$ into the sea (Fig. 4, Hathaway et al., 1979; Groen et al. 2000).

Prime examples are the East Coast of the US and the coasts of Suriname and Indonesia. Kooi \& Groen (2001) recently carried out mathematical and numerical analyses for variable-density flow and transport, which show that submarine outflow of fresh water derived from the continent (steady state condition) is not able to explain the presence of these offshore brackish waters. Even under very favourable conditions of a high permeability aquifer that extends into the offshore and that is capped by a low permeability confining layer and high topographic heads at the

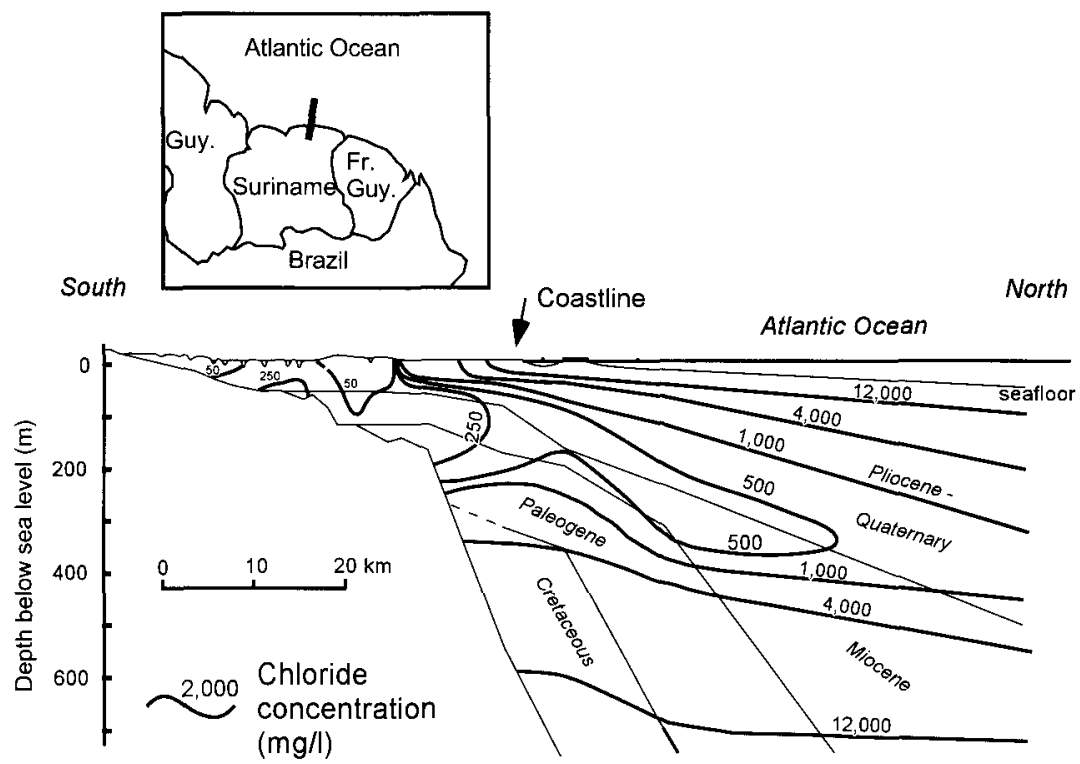

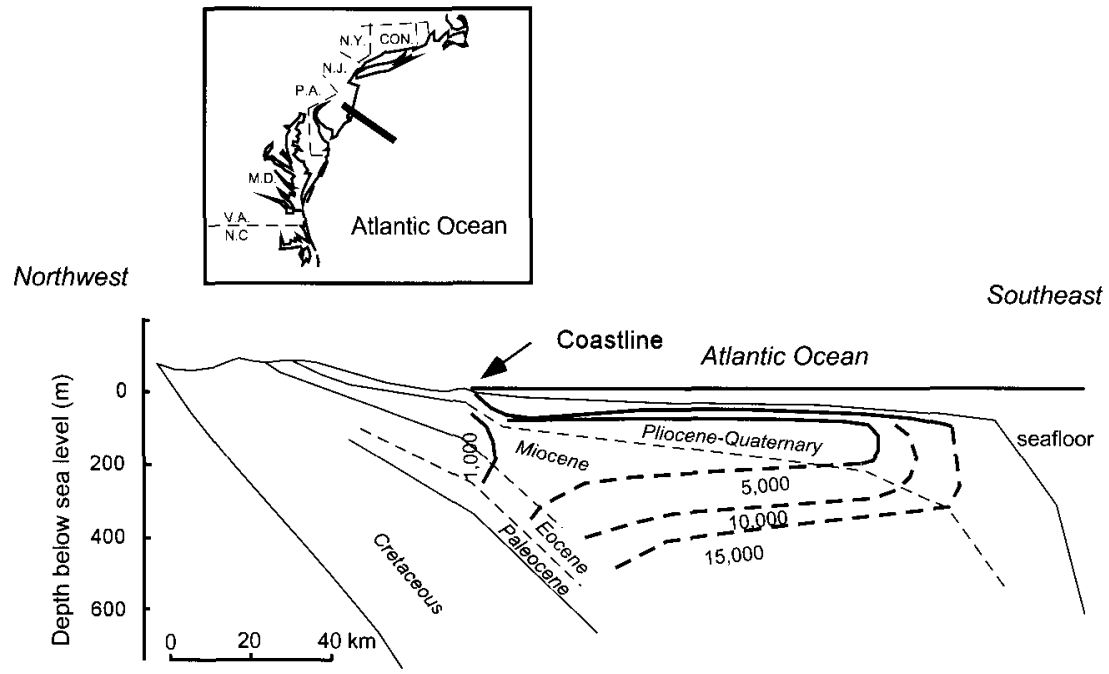

Fig. 4. Offshore occurrences of fresh and moderately brackish groundwater. Top: Suriname. Bottom: New Jersey. Modified after Kooi et al. $(2000)$. 
coastline, fresh water does not tend to extend more than $10 \mathrm{~km}$ beneath the sea under steady state flow conditions. This suggests that the distal offshore fresh and brackish waters are transient features that are relics of former low sea levels. During the Weichselian $(100,000-10,000 \mathrm{BP})$, sea level was, on average, 50 $\mathrm{m}$ lower than at present with a minimum of -100 to $-130 \mathrm{~m}$ during the last glacial maximum (LGM) between 25,000 to 15,000 BP. During this long period, shorelines were located several tens to hundreds of kilometres seaward of the present coastlines and large parts of the continental shelves were exposed to recharge with meteoric water, causing freshening of the pore waters. Age dating of groundwater in the coastal plains near Paramaribo and Jakarta shows that they are indeed of Late Weichselian age (Groen et al., 2000). Moreover, observations of groundwater heads of the deeper aquifers at Nantucket Island (Kohout et al., 1977) and Suriname (Groen, 1998) indicate stagnant conditions or even landward gradients, providing additional evidence that these offshore meteoric groundwater wedges are not related to active flow systems with onshore recharge.

Groen et al. (2000) used groundwater flow modelling to study freshening of the pore waters in the shelf at Suriname during the Weichselian using boundary conditions that are based on paleohydrologic indicators. They found that groundwater movement of the primary flow system (due to the overall shelf gradient) was too slow to reproduce the observed deep flushing of the aquifers. Moreover, this primary flow system could not explain the observed meteoric waters beyond $50 \mathrm{~km}$ offshore, an area that was exposed for a period of 10,000 years only during the LGM. Incorporating secondary flow systems in the model associated with deeply incised rivers and gullies in the

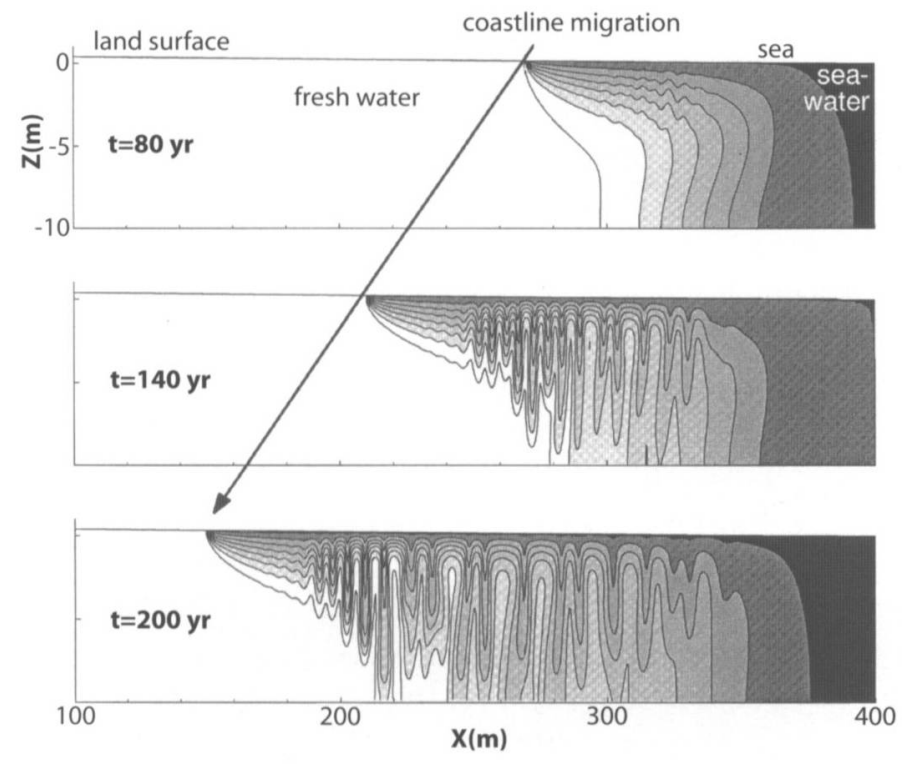

Weichselian surface (for which there is ample evidence) provided much improved results.

During the Holocene (12,000 to 6,000 BP) sea level rose some $130 \mathrm{~m}$ and in many places the coastline rapidly moved inland (transgressed) with a speed 1 to $2 \mathrm{~km} / 100 \mathrm{yr}$, often over distances of more than 100 $\mathrm{km}$. Kooi et al. (2000) carried out numerical model simulations to study the factors which control salinisation during transgression of the sea. They found that Holocene trangression rates were often sufficiently high to cause the fresh/salt transition zone to lag behind coastline migration. For permeable sediments, salinisation occurs relatively fast by vertical intrusion of seawater plumes (fingering). However, only relatively minor low permeability clay layers suffice to greatly reduce the salinisation rates and to preserve low salinity waters far offshore for very long periods of time. This is illustrated in Fig. 5 where a $0.5 \mathrm{~m}$ thick clay layer is present at the seafloor (salinity increases with darkness of shading).

In Suriname, thick Late Pleistocene and Holocene clays have led to quasi-stagnant offshore and coastal paleowaters that are subjected to salinisation by downward and upward diffusive salt transport. Groen et al. (2000) carried out diffusion modelling of vertical profiles of chemical and isotopic tracers $\left({ }^{37} \mathrm{Cl}\right)$ in these sediments and found that they are in excellent agreement with the Holocene transgression/regression history of the coastal plain. Post et al. (2000) carried out a similar study for data from the southern North Sea using ${ }^{18} \mathrm{O}$ as a tracer.

\section{Onshore saline waters}

Analogous to the formation of fresh and brackish waters in the offshore during sea-level low stands, saline

Fig. 5. Numerical simulation of sea-water intrusion during transgression. Salinity increases with darkness of shading. A $0.5 \mathrm{~m}$ thick clay layer at the seafloor protects the underlying aquifer against rapid salinization. A zone of brackish groundwater develops in the offshore. Modified after Kooi et al. (2000). 


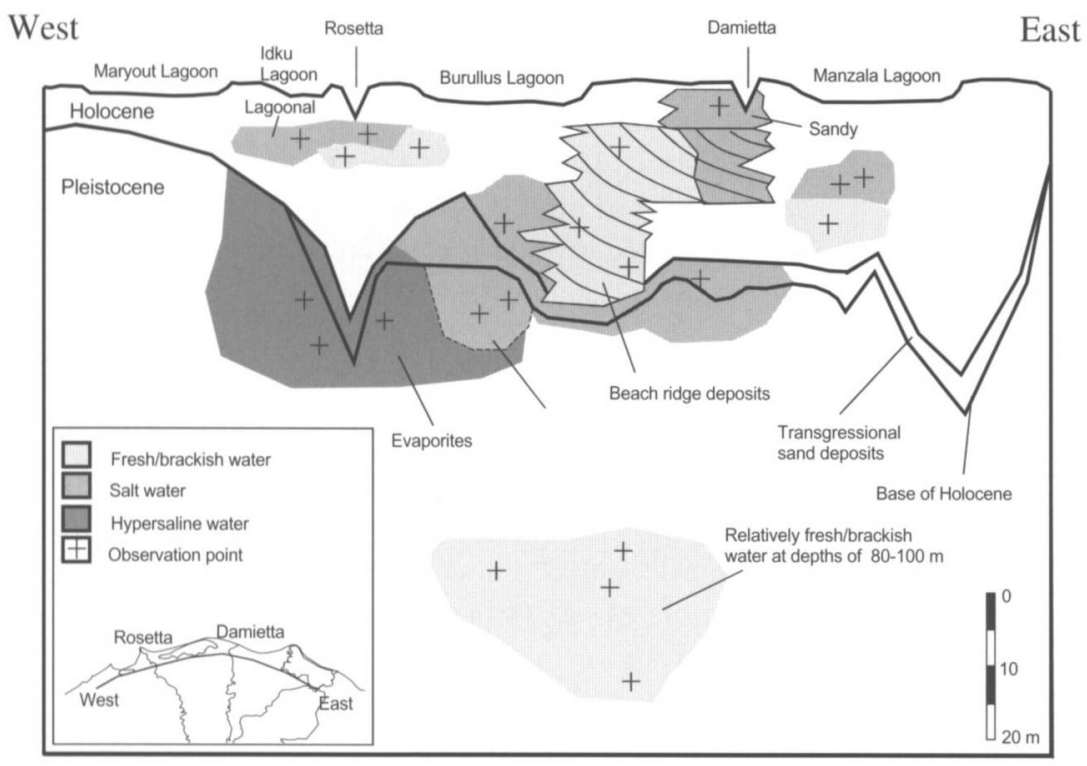

Fig. 6. Schematic East-West cross-section through the northern Nile Delta showing the complexity of the salinity distribution and its relationship with depositional environment.

waters can be preserved on land following sea-level highs (e.g., Manheim \& Horn, 1968; De Vries, 1981; Custodio et al., 1987). Saline waters can further be the product of dissolution of evaporite deposits that are often related to lagoonal conditions (e.g., Vengosh $\&$ Rosenthal, 1994). To understand and predict the presence of onshore saline groundwaters, knowledge of the geological history of transgression and regression as well as enviroment of deposition obviously is extremely useful. The intimate relationship between groundwater salinities and paleo-environmental conditions is illustrated in Fig. 6 for a cross-section through late Pleistocene and Holocene deposits of the northern part of the Nile Delta.

The figure shows that hypersaline waters are found in areas that host evaporite layers (sabhkas and salt pans); salt water is associated with deposits of marine origin (lagoons) and fresh waters occur in fossil dune complexes. Saline waters near the base of the Pleistocene Nile Delta aquifer system (not shown in Fig. 6) may provide an example of the action of geological processes that are less intuitive. These saline waters, which have been inferred from resistivity logs from deep boreholes, seem to extend about $100 \mathrm{~km}$ from the present coastline, halfway to the apex of the delta at Cairo. Because the salt-water thickness increases seaward, it has been interpreted to represent a classical, stationary seawater wedge (Sherif, 1999). However, preliminary numerical modelling incorporating former coastline changes suggests that such a wedge would not have developed since the Weichselian period of low sea levels. It may, therefore, be hypothesised that the wedge of saline water originates from deep Mio-Pliocene brines. These brines may ascend along faults though the Pliocene aquitard below the base of the Pleistocene aquifer system, driven upward by ex- tremely high compaction-related fluid pressures that have been documented to occur in the underlying basin units. In general terms, this hypothesis suggests that in situations of this kind the nature and location of a lower model boundary must be carefully considered.

\section{Implications for groundwater management}

Management of groundwater resources for large coastal areas obviously requires quantitative hydrogeological models of the management domain. These models are important not only to describe the current condition, but more in particular to carry out predictions of future development for different human development scenarios. Whether or not predictions of these scenario studies are realistic depends, apart from the accuracy of human development projections, on the extent to which the current system, which acts as the initial condition for the scenario studies, is accurately represented by the model. The initial condition consists of the head/pressure field and the water quality distribution. Uncertainties or errors in the initial condition, as well as in the characterization of hydraulic properties, will affect the validity of predictions of scenario studies. The following conclusions can be drawn based on the material presented above.

1. Considering sediment loading as a cause of head/pressure generation may help in the characterization of the distribution of hydraulic parameters. The example from Suriname illustrates that if sediment loading is not considered, a very unlikely conduit may have to be assumed between the aquifer at the coast and a recharge area far inland in order to account for the observed heads. Such an assumption might seriously affect predictions of the 
long-term response of the coastal groundwater system to development of this aquifer because recharge would be overestimated. Similar, albeit less severe repercussions of ingorning sediment loading may be expected in situations of semi-confined aquifers that outcrop in and are recharged in a topographically elevated area due to over/underestimation of the hydraulic resistance/ leakance of the confining layer.

2. Knowledge of the paleohydrological evolution of a coastal area and, in particular, the history of coastline migration is very useful to characterize the current salinity distribution of groundwater. The extensive knowledge that is often available at geological surveys and in academia is extremely valuable to set up efficient sampling strategies to get a better characterization. Also, with paleohydrological information, realistic process-based predictions can be made of groundwater salinity where observational data are lacking or scarce. A notable example is relationship between depositional environment and salinity patterns in the Holocene coastal plain of the Nile Delta. If geological information were not available, inter- and extrapolation of the available salinity data would have to be based on 'ignorant' mathematical algorithms. A second notable example is the occurrence of huge volumes of fresh and brackish groundwaters offshore Suriname. Due to heavy groundwater extraction in the coastal plain, seawater intrusion was expected to end the use of this resource a decade ago, and plans were underway for groundwater development further inland. These projections were based on the 'engineering view' of seawater intrusion based on the notion that the fresh-salt transition always takes the form of landward dipping interface from the current coastline location. Geological process considerations indicate that the transition zone is actually located some $80 \mathrm{~km}$ further to the north beneath the Atlantic Ocean. As offshore meteoric groundwater has a remarkably low salinity in some places, it may even be a viable source for future water supply. Investigations of the possibility are underway. Though it is essentially a form of mining, recovery of offshore paleowater should not be discarded outright. First of all, the resources are vast and could last for hundreds to thousands of years. Secondly, and perhaps more importantly, if not used, these paleowaters would disappear naturally by submarine groundwater discharge or salinisation by diffusion. It is remarkable that although saline waters onshore related to former transgression phases are known for a long time, offshore meteoric water occurrences seem not to have been anticipated until they were encountered by chance.
3. The management of groundwater resources for large coastal domains requires the development of realistic hydrogeological models that, in their characterization of initial conditions and the distribution of hydraulic parameters, take into account knowledge about geological processes that occurred in the sometimes-distant past. This geological approach to groundwater hydrology does not merely imply a backward shift in time of the starting point of the studied hydrogeological processes. It also entails expansion of the spatial domain of study into the offshore and to greater depth.

\section{Acknowledgements}

The authors wish to thank Chris Neuzil and an anonymous reviewer for their constructive comments.

\section{References}

Committee on Opportunities in the Hydrologic Sciences, Water Science and Technology Board, Commission of Geosciences, Environment, and Resources, National Research Council, 1991. Opportunities in the Hydrologic Sciences, National Academy Press (Washington D.C.): 348 pp.

Custodio, E., Bruggeman, G.A. \& Cotecchia, V., 1987. Groundwater problems in coastal areas. Studies and Reports in Hydrology 35. UNESCO (Paris): $650 \mathrm{pp}$.

De Vries, J.J., 1981. Fresh and salt groundwater in the Dutch coastal area in relation to geomorphological evolution. Geologie en Mijnbouw 60: 33-368.

Dickinson, G., 1953. Geological aspects of abnormal reservoir pressures in Gulf Coast Louisiana. American Association of Petroleum Geologists Bulletin 37: 410-432.

Groen, J., 1998. Hydrogeological investigations in Suriname. In: Wong, Th. E., et al. (eds): The History of earth sciences in Suriname. Netherlands Institute of Applied Geoscience TNO \& Royal Netherlands Academy of Arts and Sciences: 129-174.

Groen, J., Velstra, J. \& Meesters, A.G.C.A., 2000. Salinization processes in paleowaters in coastal sediments of Suriname: evidence from $\delta^{37} \mathrm{Cl}$ analyses and diffusion modelling. Journal of Hydrology 234: 1-20.

Hathaway, J. C., Poag, C. W., Valentine, P. C., \& Al, E., 1979. U.S. Geological Survey core drilling on the Atlantic Shelf. Science 206: 515-527.

Hunt, J.M., 1990. Generation and migration of petroleum from abnormally pressured fluid compartments. American Association of Petroleum Geologists Bulletin 74: 1-12.

Kohout, F. A., Hathaway, J. C., Folger, D. W., Bothner, M. H., Walker, E. H., Delaney, D. F., Frimpter, M. H., Weed, E. G. A., \& Rhodehamel, E. C., 1977. Fresh groundwater stored in aquifers under the continental shelf: implications from a deep test, Nantucket Island, Massachusetts. Water Resources Bulletin 13: 373-386.

Kooi, H., 1997. Insufficiency of compaction disequilibrium as the sole cause of high pore fluid pressures in pre-Cenozoic sediments, Basin Research 9: 227-241.

Kooi, H., 1999. Competition between topography- and compaction-driven flow in a confined aquifer: some analytical results. Hydrogeology Journal 7: 245-250.

Kooi, H. \& De Vries, J., 1998. Land subsidence and hydrodynamic 
compaction of sedimentary basins, Hydrology and Earth System Sciences 2: 159-171.

Kooi, H. \& Groen, J., 2001. Offshore continuation of coastal groundwater systems; predictions using sharp-interface approximations and variable-density flow modelling. Journal of Hydrology 246: 19-35.

Kooi, H., Groen, J. \& Leijnse, A., 2000. Modes of sea-water intrusion during transgressions. Water Resources Research 36: 35813589.

Manheim, F.T. \& Horn, M.K., 1968. Composition of deeper subsurface waters along the Atlantic continental margin. Southeast Geology 9: 215-236.

Neuzil, C.E., 1986. Groundwater flow in low-permeability environments. Water Resources Research 22: 1163-1195.

Neuzil, C.E., 1994. How permeable are Clays and Shales? Water Resources Research 30:145-150.
Post, V.E.A., Hooijboer, A.E.J., Groen, J., Gieske, J.M.J. \& Kooi, H., 2000. Pore water chemistry of clay layers in the southern North Sea: clues to the hydrogeological evolution of coastal areas. In: Sadurski A. (ed.): Hydrogeology of the coastal aquifers; Proceedings of the $16^{\text {th }}$ SWIM Conference, Miêdzyzdroje, Poland 12-15 June 2000. Nicholas Copernicus University (Torun, Poland): 127-132.

Powley, D.E., 1990. Pressures and hydrogeology in petroleum basins. Earth Science Reviews 29: 215-226.

Sherif, M., 1999. Nile Delta aquifer in Egypt. In: Bear, J. et al. (eds): Seawater intrusion in coastal aquifers - concepts, methods and practice, Kluwer (Dordrecht): 559-590.

Vengosh, A. \& Rosenthal, E., 1994. Saline groundwater in Israel: its bearing on the water crisis in the country. Journal of Hydrology 156: $389-430$. 